\title{
NANO MODIFIED HIGH VOLUME FLYASH SELF COMPACTING CONCRETE
}

\author{
Hemalatha, $\mathbf{T}^{\mathbf{1}}$, Maitri Mapa ${ }^{2}$, Vinoth Kumar $\mathbf{P}^{\mathbf{3}}$ \\ ${ }^{1}$ Scientist, CSIR-Structural Engineering Research Centre, CSIR Complex, Taramani, Chennai-113 \\ ${ }^{2}$ Quick Hire Scientist, CSIR-Structural Engineering Research Centre, CSIR Complex, Taramani, Chennai-113 \\ ${ }^{3}$ Project Student CSIR-Structural Engineering Research Centre, CSIR Complex, Taramani, Chennai-113
}

\section{Synopsis}

Self compacting concrete (SCC) is an innovative concrete to tackle the problem of concreting through dense reinforcement. Adoption of SCC offers substantial benefits in enhancing construction productivity, reducing overall cost, and improving the work environment. The present work investigates the compressive strength of SCC by replacing high volumes of Portland cement by fly ash. Studies are conducted to investigate the influence of different replacement levels of cement $(20 \%, 40 \%, 60 \%$ and $80 \%)$ with fly ash (class F). The results revealed that the fresh and hardened properties of SCC incorporating upto $40 \%$ fly ash as replacement of cement (CE40FA) are not significantly affected. However, it was noticed that the early age strength is significantly affected even at $40 \%$ replacement. To overcome the drawbacks of using high volume fly ash (HVFA), the additions such as lime water, lime sludge and nano $\mathrm{CaCO} 3$ etc. are added to HVFA SCC. It is understood that the additions of lime water, lime sludge and nano $\mathrm{CaCO} 3$ in $\mathrm{CE} 40 \mathrm{FA}$ mix helps in improving the early age strength at 7 days without affecting the later age strength at 28 days. In CE40FA, SCC containing lime water showed about 38\% higher compressive strength at 7 days. The addition of 5\% lime sludge and $1 \%$ nano $\mathrm{CaCO} 3$ in $\mathrm{CE} 40 \mathrm{FA}$ also showed about $31 \%$ and $58 \%$ increase in the strength compared to the ordinary concrete at 7 days, respectively.

Key words: High volume fly ash, mechanical properties, nano CaCO3, Lime sludge $* * *$

\section{INTRODUCTION}

Self-compacting concrete (SCC) is considered as a concrete which can be placed and compacted under its self-weight with little or no vibration effort. It is used to facilitate and ensure proper filling and good structural performance of restricted areas and heavily reinforced structural members. Adoption of SCC offers substantial benefits in enhancing construction productivity, reducing overall cost, and improving work environment. When the volume of coarse aggregate in the concrete is excessive, the opportunity of contact between coarse aggregate particles increases greatly, causing interlocking and the possibility of blockage on passing through spaces between steel bars. Therefore, the first point to be considered when designing SCC is to restrict the volume of coarse aggregate. This reduction necessitates the use of higher volume of cement which increases the cost, besides resulting in undesirable temperature rise. Hence, cement should be replaced by other mineral admixtures like Ground Granulated Blast Furnace Slag, Fly Ash, etc. The usage of mineral admixtures in the production of SCC not only provides economical benefits but also reduces heat of hydration. It is also known some mineral admixtures may improve rheological properties and reduce thermallyinduced cracking of concrete due to the reduction in the overall heat of hydration and increases the workability and long-term serviceability of concrete.

Binu et al. [1] presented a rational method of mix design based on the material characteristics for various grades of
SCC by incorporating high volume fly ash as mineral admixture. Fly ash based SCC has proven records of long term strength and durability as it imparts a continuous hardening systems to the concrete. They also [1] studied the effect of fly ash on the early age strength in SCC, as, it is essential to study the development of strength at early ages of curing which may prove to be a significant factor for the removal of formwork. Benefits of high volume fly ash concrete are extensively researched and reported widely in literature [2-6]. In this study, influence of various replacements levels of fly ash on compressive strength of self compacting concrete has been studied.

\section{MATERIALS AND METHODS}

Ordinary Portland cement (OPC) complying with IS standard and fly ash conforming to ASTM C618 are used in this study. The chemical composition of OPC and fly ash are presented in Table 1. Natural sand (0-3 mm) and gravel(3$12.5 \mathrm{~mm}$ ) are used in the preparation of SCC mixtures. Sulfonate based superplasticizer (SP) is used in enhancing the workability. 
Table 1. Chemical composition Cement and Fly ash (\%)

\begin{tabular}{|c|c|c|c|c|c|c|c|c|c|}
\hline $\begin{array}{c}\text { Chemical } \\
\text { composition }\end{array}$ & $\mathrm{SiO}_{2}$ & $\mathrm{Al}_{2} \mathrm{O}_{3}$ & $\mathrm{CaO}$ & $\mathrm{Fe}_{2} \mathrm{O}_{3}$ & $\mathrm{MgO}$ & $\begin{array}{c}\text { Free } \\
\mathrm{CaO}\end{array}$ & $\begin{array}{c}\mathrm{Na}_{2} \mathrm{O}+ \\
\mathrm{K}_{2} \mathrm{O}\end{array}$ & $\mathrm{SO}_{3}$ & Loss of ignition \\
\hline Cement & 21.0 & 5.1 & 64.1 & 3.1 & 2.5 & 0.8 & 1.0 & 2.2 & 0.6 \\
\hline Fly ash & 64.03 & 15.50 & 4.62 & 6.50 & 3.00 & - & - & - & 4.35 \\
\hline
\end{tabular}

\subsection{Mixing sequence, specimen preparation and} curing

Firstly, two thirds of mixing water is added to the mixer followed by the addition of fine, coarse aggregate, cement and fly ash. Ingredients are mixed for $2 \mathrm{~min}$ and when a uniform mix is obtained, the remaining water with required amount of SP are added to the mix and mixed for another 3 min. Later, the machine is stopped for a period of $2 \mathrm{~min}$ to allow the mix to rest. Again the mixer is switched on and mixed for final $2 \mathrm{~min}$ before testing for its fresh properties. Total of $9 \mathrm{~min}$ is required for the complete mixing of SCC. A total of six cubes (three each for 7 and 28 days), six cylinders, and three flexure beams are prepared and tested at 28 days.

\section{EXPERIMENTAL PROCEDURE}

\subsection{Trial Mixes}

A systematic study is carried out to evaluate the effect of percentage replacement of fly ash on compressive strength of self compacting concrete (SCC). Mixes are prepared with $20 \%, 40 \%, 60 \%$ and $80 \%$ replacement of cement by Class $\mathrm{F}$ fly ash. Many trials were made to arrive the mixture proportioning for a control mix with $20 \%$ replacement of fly ash. The mixture proportion satisfying the fresh properties such as flow ability, passing ability and segregation resistance is finalised as control SCC. Mixture proportion arrived for control SCC is shown in Table 2.

Table 2. Mixture Proportioning of control SCC in $\left(\mathrm{kg} / \mathrm{m}^{3}\right)$

\begin{tabular}{|c|c|c|c|c|}
\hline Cement & Fly ash & $\begin{array}{c}\text { Fine } \\
\text { aggregate }\end{array}$ & $\begin{array}{c}\text { Coarse } \\
\text { aggregate }\end{array}$ & Water \\
\hline 428.4 & 107.1 & 861.4 & 754.6 & 215.5 \\
\hline
\end{tabular}

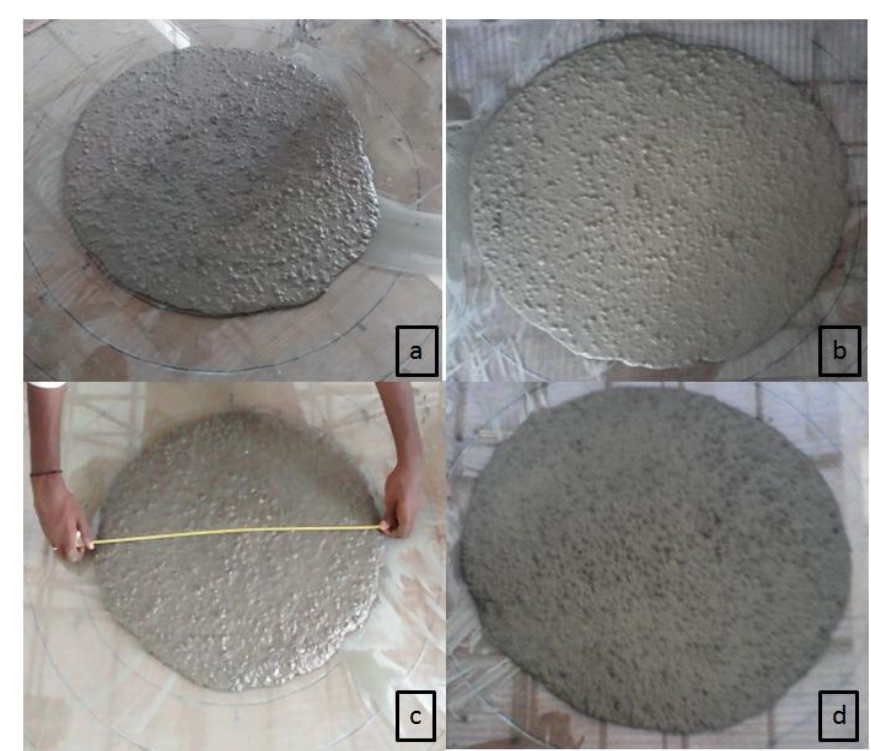

Fig 1. Horizontal flow measured for a) 20FA b) 40FA c) 60FA d) $80 \mathrm{FA}$

During each trial the horizontal spread of concrete is measured as shown in Figure 1 and the mixture which showed the horizontal spread in the range of $650-800 \mathrm{~mm}$ for each mix is qualified as self compacting concrete.

Cement when replaced with mineral additions such as fly ash in high percentages results in a concrete with lower compressive strength. However, with optimized mix proportions and with the incorporation of superplasticizers, economical concretes can be obtained with enhanced strength and durability. According to the reported studies, with the increase in the replacement level of fly ash, compressive strength decreases. However, in this study, it is observed that there is no significant reduction in strength upto $40 \%$ replacement. Whereas above $40 \%$, say $60 \%$ and $80 \%$, the drastic reduction in compressive strength, especially at early age ( 7 days of curing) is noticed as shown in Table 3.

Table 3. Compressive strength of SCC mixes

\begin{tabular}{|c|c|c|c|}
\hline \multirow{2}{*}{ Mix } & \multicolumn{2}{|c|}{ Average Compressive Strength (MPa) } & \multirow{2}{*}{$\begin{array}{c}\text { increase in } \\
\text { strength }\end{array}$} \\
\cline { 2 - 3 } & $\mathbf{7 ~ d a y s}$ & $\mathbf{2 8 ~ d a y s}$ & 15 \\
\hline CE20FA & 43.33 & 51.15 & 02 \\
\hline CE40FA & 43.00 & 44.18 & 47 \\
\hline CE60FA & 25.66 & 48.15 & 49 \\
\hline CE80FA & 12.25 & 24.20 & 47 \\
\hline
\end{tabular}


Fly ash has high pozzolanic value and due to that reason it can reacts with $\mathrm{Ca}(\mathrm{OH}) 2$ produced during cement hydration to form more calcium silicate hydrate $(\mathrm{CSH})$. This $\mathrm{CSH}$ is believed to be responsible for the development of strength in concrete. Because of this reason, the strength development in fly ash incorporated concrete is expected at long term. In this study, below $50 \%$ replacement, it is found that the early age strength ( 7 days strength) is high but at long term (at 28 days) there is no significant improvement in the strength. $20 \%$ and $40 \%$ replacement showed only $15 \%$ and $2 \%$ improvement respectively from 7 to 28 days. However, at $60 \%$ and $80 \%$ replacement levels, inspite of the low early age strength, around $50 \%$ improvement in strength is observed at 28 days.

With $80 \%$ replacement, the compressive strength of CE80FA is very much reducing indicating that for the development of strength, it requires at least minimum $\mathrm{CaO}$ content. It is observed that incorporation of SCMs improves the properties at fresh state, however, it lowers the strength development especially at higher replacement levels. It is well known that the pozzolanic reaction can take place only if sufficient calcium hydroxide is available through a hydraulic reaction. Hence, the pozzolanic reaction can thus only happen after the sufficient hydraulic reaction occurs. Thus, the amount of $\mathrm{CaO}$ can be associated with strength at earlier ages whereas the silica and alumina can be associated with the strength at later ages. Hence, the availability of enough "Ca" containing materials are required initially to get desired early age strength. Therefore, an attempt has been made in this study with various calcium rich additions in SCC mix to improve the early age strength. Additions include nano calcium carbonate (nano CC), lime water and lime sludge (LS waste from paper industry). It is observed that the additions significantly altered the fresh and hardened properties of SCC, as well.

It has been noticed that even after FA incorporation, the CE20FA has sufficient $\mathrm{CaO}$ content, hence additions are made only for CE40FA and CE60 FA. The percentage additions for CE40FA and CE60FA are appropriately decided based on their calcium deficiency. For instance, in CE60FA SCC, about $1 \mathrm{gm}$ of $\mathrm{Ca}(\mathrm{OH}) 2$ is dissolved in 1 litre of water to make lime water whereas in CE40FA SCC, only about $0.65 \mathrm{gms}$ of $\mathrm{Ca}(\mathrm{OH}) 2$ is dissolved in 1 litre of water to make lime water. All the tests are conducted for fresh properties for SCC with various additions and are presented in Table 4.

Table 4. Influence of addition of lime water, lime sludge and nano $\mathrm{CaCO}_{3}$ on fresh properties of self compacting concrete

\begin{tabular}{|c|c|c|c|}
\hline S.no. & Mix & $\begin{array}{c}\text { Slump } \\
\text { flow (mm) }\end{array}$ & $\begin{array}{c}\text { V-funnel } \\
\text { (sec) }\end{array}$ \\
\hline 1 & $\begin{array}{c}\text { CE40FA+lime } \\
\text { water }\end{array}$ & 660 & 7 \\
\hline 2 & $\begin{array}{c}\text { CE60FA+lime } \\
\text { water }\end{array}$ & 720 & 8 \\
\hline 3 & CE40FA+LS & 570 & 8 \\
\hline 4 & CE60FA+LS & 625 & 9 \\
\hline 5 & CE40FA+CC & 685 & 9 \\
\hline 6 & CE60FA+CC & 720 & 10 \\
\hline
\end{tabular}

It is observed that the horizontal spread is reduced with the all the additions in both the cases (CE40FA and CE60FA) compared to without additions specimens. Further, it is found that the additions significantly improved the hardened properties at 7 days, however, depending upon the chemical properties of additions, the variation in improvement of early age strength has been noticed. The comparison of 7 days strength with and without additions are presented in Table 5.

At CE40FA specimens, the strength is improved for all the additions whereas for CE60FA specimens shows only slight increase in strength for lime water addition. No significant strength improvement for other additions has been noticed for CE60FA specimens. Hence, it is learnt from the observation that for very high replacement (more than 50\%) the various percentage of different additions should be tried for better results.

Table 5. 7 days compressive strength of self compacting concrete with and without additions

\begin{tabular}{|c|c|c|c|c|}
\hline S.No. & Mix & Additions & $\begin{array}{c}\text { Without } \\
\text { additions } \\
\text { (MPa) }\end{array}$ & $\begin{array}{c}\text { With } \\
\text { additions } \\
\text { (MPa) }\end{array}$ \\
\hline 1 & CE40FAC & \multirow{2}{*}{$\begin{array}{l}\text { Lime } \\
\text { water }\end{array}$} & 25.61 & 35.3 \\
\hline 2 & CE60FAC & & 30.71 & 33.4 \\
\hline 3 & CE40FAC & \multirow{2}{*}{$\begin{array}{l}\text { Lime } \\
\text { sludge }\end{array}$} & 25.61 & 33.56 \\
\hline 4 & CE60FAC & & 30.71 & 20.5 \\
\hline 5 & CE40FAC & \multirow{2}{*}{$\begin{array}{c}\text { Nano } \\
\mathrm{CaCO}_{3}\end{array}$} & 25.61 & 40.7 \\
\hline 6 & CE60FAC & & 30.71 & 19.8 \\
\hline
\end{tabular}

With the addition of lime water in fly ash incorporated SCC mixes, early age strength has been significantly improved in CE40FA mixes. It is noticed that the compressive strength increased by $37.8 \%$ at 7 days in comparison without additions in CE40FA. But there is no significant increase in strength improvement at 28 days compared to control SCC. In CE60FA with lime water mix, a reduction in the measured compressive strength values are noticed at 7 and 28 days as presented in Table 5 and 6 . It is found that the addition of lime water greatly helps in improving the early age strength of CE40FA mix.

Table 6. 28 days compressive strength of self-compacting concrete with and without additions

\begin{tabular}{|c|c|c|c|c|}
\hline S.No. & Mix & Additions & $\begin{array}{l}\text { Without } \\
\text { additions } \\
\text { (MPa) }\end{array}$ & $\begin{array}{l}\text { With } \\
\text { additions } \\
\text { (MPa) }\end{array}$ \\
\hline 1 & CE40FAC & \multirow{2}{*}{$\begin{array}{l}\text { Lime } \\
\text { water } \\
(\mathrm{LW})\end{array}$} & 49.5 & 50.3 \\
\hline 2 & CE60FAC & & 35.63 & 33.4 \\
\hline 3 & CE40FAC & \multirow{2}{*}{$\begin{array}{l}\text { Lime } \\
\text { sludge } \\
\text { (LS) }\end{array}$} & 49.5 & 48.96 \\
\hline 4 & CE60FAC & & 35.63 & 26.4 \\
\hline 5 & CE40FAC & \multirow{2}{*}{$\begin{array}{l}\text { Nano } \\
\mathrm{CaCO}_{3}\end{array}$} & 49.5 & 49.2 \\
\hline 6 & CE60FAC & & 35.63 & 31.76 \\
\hline
\end{tabular}


Further, the investigation on fly ash replaced concrete with addition of lime sludge in CE40FA mixes revealed that the compressive strength increases by $31 \%$ at 7 days compared to control mix. Similar to lime water addition, lime sludge addition also does not help in improving strength at 28 days. In CE60FA with lime sludge mix, a reduction in the measured compressive strength values noticed at both 7 and 28 days as presented in Table 5 and 6.

The effect of incorporation of nano- $\mathrm{CaCO} 3$ on the compressive strength development is also studied. The concrete containing $1 \%$ nano- $\mathrm{CaCO} 3$ addition also exhibited significantly higher compressive strength at 7 days, but there is no strength improvement at 28 days. It is noticed that an improvement of about 58\% of compressive strength in CE40FAC at 7 days with $1 \%$ of nano-CaCO3.

\section{CONCLUSIONS}

It is found that with increase in fly ash content, the fresh properties of SCC are improved while hardened properties are reduced. With increased replacement of cement, cementitious property is reduced which results in the reduction of strength especially the early age strength. To overcome this drawback, various additions with calcium rich materials are attempted and it is found that significant improvement in the early age strength of SCC is achieved with nano calcium carbonate and lime water incorporation without compromising the fresh properties as recommended by EFNARC standard for SCC.

\section{ACKNOWLEDGEMENT}

This paper is being published with the kind permission of Director CSIR-SERC. Some of instrument from innovation complex has been used.

\section{REFERENCES}

[1] Binu Sukumar, K. Nagamani and R. Srinivasa Raghavan, Evaluation of strength at early ages of selfcompacting concrete with high volume fly ash. Construction and Building Materials, 2, 1394-1401, 2008.

[2] V.M. Malhotra. Superplasticized fly ash concrete for structural applications. Concrete International, 8:28-31, 1986.

[3] V.M. Malhotra. Durability of concrete incorporating high-volume of low-calcium (ASTM class F) fly ash. Cement and Concrete Composites, 12(4):271-277, 1990.

[4] Rafat Siddique. Performance characteristics of highvolume class f fly ash concrete. Cement and Concrete Research, 34:487-493, 2004.

[5] C.S. Poon, L. Lam, and Y.L. Wong. A study on high strength concrete prepared with large volumes of low calcium fly ash. Cement and Concrete Research, 30:447-455, 2000.

[6] Bilodeau A. and V.M. Malhotra. High-volume fly ash system: Concrete solution for sustainable development. ACI materials Journal, 97:41-48, 2000. 